\title{
Car following techniques: the role of the human factor reconsidered
}

\author{
$M^{\mathrm{a}}$ Teresa Blanch Micó, Antonio Lucas Alba, Teresa Bellés Rivera, Ana Mª Ferruz \\ Gracia
}

Facultad de Ciencias Sociales y Humanas, Universidad de Zaragoza, Spain

Oscar Melchor Galán

Impactware, Spain

\section{Luís C. Delgado Pastor}

Facultad de Ciencias Humanas y de la Educación, Universidad de Zaragoza, Spain

Francisco Ruíz Jiménez

Departamento de Psicología, Fundación Universitaria Konrad Lorenz, Colombia

Mariano Chóliz Montañés

Departamento de Psicología Básica, Universitat de València, Spain

\begin{abstract}
Engineering and psychophysiological car following models emerge in the late 1950s (Saifuzzaman \& Zheng, 2014). Such models differ in their ground concepts and explanatory mechanisms, but both assume a fundamental tenet: following each other, drivers invariably attempt to couple, keeping safety distance. More recent models focus on the spontaneous emergence of traffic jams that results from the properties of a system of interacting vehicles (i.e., without bottlenecks). In an experimental setting Sugiyama et al., (2008) have successfully recreated the conditions that allow the observation of the typical soliton wave going backwards through several car clusters. When certain speed, density and inter-vehicular distance join, so do traffic jams. Some of us have built upon these and other factors (e.g., wave movement in nature) exploring the mathematical properties of a system with three incognita that also needs three variables to be solved (Melchor \& Sánchez, 2014). Two canonical car-following techniques emerge as a consequence: Driving to keep safety Distance (DD) vs Inertia (DI). Also a basic question: can drivers actually understand and follow either way, or do they stick to a basic normative driving behavior? This paper summarizes the results after three experimental studies done with a driving simulator. Several performance measures from individual drivers (accelerations, decelerations, average speed, distance to leader, and so on) were taken. As an overall indicator, results consistently announce in the three studies that DI trips consume less fuel (about 20\%) than DD ones.
\end{abstract}

\section{BACKGROUND}

\subsection{Driver, vehicle, road: sketching some notes on a familiar triangle}


By the end of the XIX Century the classical triangle was made of the coachman, the stagecoach and unpaved roads (Ranney, 1994). The automobile came then, about 1886, and the whole triangle underwent the first transformation in hundreds of years. First automobiles were slow, around $16 \mathrm{~km} / \mathrm{h}$, but speed grew quickly. The need for drivers to learn and for roads to improve was soon evident and traduced to safety issues, accidents and casualties, but automobile drivers were minority. In 1908 Henry Ford said "I will build the car for the great multitude" and so he did, the Ford T. In the 1930s Model T was the first successful mass consumption automobile. Then, in the 1930s and 1940s the first congestions came, grew and became habitual. The need to improve the whole triangle, roads in particular, became acute, and also the main traffic problems: safety and mobility (Lucas, 2009). Perhaps the Federal-Aid Highway Act enacted by President Eisenhower in 1956 for the construction of 41000 miles of the Interstate Highway System is one of the soundest examples of the perception of that need at that time (Weingroff, 1996).

\subsection{The way forward: Newtonian and psychophysical parameters}

Building roads is a sound science, perhaps epitomized by the Highway Capacity Manual (TRB, 2010). Back in the 1940s and 1950s a growing car-society had to decide the way forward with roads, considering the expected number of drivers that would use them. The speed of cars is an important issue concerning road geometry and how wide lanes should be, for example. The number of expected cars per hour in a given road section too. Early models where indeed Newtonian (Boer, 1999), reckoning a safe follow-up distance that should be assumed (considering reaction time and pavement friction) in order to avoid collisions, no matter what the leading car could do. The subsequent car-following models would improve adding complexity in terms of the intervening factors and particularly on the parameters nuancing their effect on the equations (Brackstone \& McDonald, 1999). Since the early 1960s two explanatory trends, the engineering perspective and the human factors one have evolved in parallel (Saifuzzaman \& Zheng, 2014). Both approaches share a main axiom: there is a safe distance for car following that drivers generally tend to adopt. Action Point psychophysical models explain the way it happens considering basic visual parameters. Indeed, individual drivers need to calculate if they are too far or too close from the leading vehicle somehow (the just noticeable difference), and car-following is a dynamic activity based on a visual tradeoff (Pariotta \& Biffulco, 2015). However when doing so drivers also follow a basic, official recommendation: keep safety distance.

\subsection{A turning point: perhaps in Nagoya}

Such recommendation is rooted in the engineering and human rationale shaping historical programs as the Federal-Aid Highway Act. Many amazing achievements have gone through since, and modern citizens drive more and more safely. But congestions remain, and so pervasively that have earned a metaphysical label: the phantom traffic jam (Gazis \& Herman, 1992). Fortunately, before some sect embraces the emerging myth, a number of physics and engineers have pushed a complementary view of car-following. Why should traffic jams appear in the absence of a bottleneck? The departure point is not the micro- 
analysis of the coupled vehicles moving anymore, now "traffic flow is investigated as a dynamical phenomenon of a many-particle system" (Sugiyama et al., 2008; p. 2). The Nagoya Experiment created a traffic jam artificially. A number of drivers drive in a closed circular circuit of $230 \mathrm{~m}$. Participants received a basic instruction: follow the vehicle ahead in safety in addition to trying to maintain your cruising velocity. And so they drive and keep free flow. But when the number of drivers is 22 , the free flow is easily broken by fluctuations tripping upwards, through the flow. The homogeneity becomes disturbed and, eventually, several vehicles are forced to stop completely for a moment.

\section{DRIVERS AND CAR-FOLLOWING: RECONSIDERING THEIR ROLE}

\subsection{Nature, living beings and waves}

The Nagoya study delves on a physical-mathematical reconsideration of car-following that has also been analyzed by some of us (Melchor \& Sánchez, 2014). Nagoya's drivers have perhaps something to learn of Thaumetopoea pityocampa caterpillars that keep turning in a circle one after the other for 12 consecutive hours before disaggregating (Fitzgerald, 2003; Gil, 2015). No wonder why we call them procesionarias in Spain.

But even those owing some hours to the study and comprehension of physics may see that what is at stake here is longitudinal mechanical waves (Cromer, 1981). Keep safety distance is a good recommendation for coupling vehicles, but as far as more than two consecutive cars follow, the cars themselves turn into a nearly perfect medium for wave transmission. This is nicely observed in the videos taken by Sugiyama et al., when -at some point- the oscillatory nature of flowing cars spreads, backwards, in the form soliton wave of $25 \mathrm{~km} / \mathrm{h}$. Cars are platooning so nicely that drivers, by virtue of the recommendation follow the vehicle ahead in safety, cannot avoid propagating the corresponding disturbances.

\subsection{Providing drivers with new tools against their own collective entropy}

Sugiyama et al. (2008) claim is the experimental production of a traffic jam, without bottleneck, out of nothing. Indeed, the trick of the phantom traffic jam has been discovered but it keeps annoying us. Perhaps the phantom reveals another undesired consequence of humana conditio: drivers just keep driving as they can and no other outcome is possible, i.e., the phantom is but the first sign of the entropy approaching a platoon that is ready for it. There is hope, however, as Norbert Wiener explained "the process by which we living beings resist the general stream of corruption and decay is known as homeostasis." (Wiener, 1989; p. 95). To set up the principle of homeostasis or allostasis (achieving stability through change) something should be done with the transmission of disturbances.

Considering wave mechanics, either we eliminate disturbances or we deal with the very medium that transmit them -the car-following platoon. The former are difficult to deal with, considering chance, but not the latter. The possibility against a leading oscillatory car 
(shockwave transmission) is a car that follows practicing some kind of shockwave damping. In this way, we reverse the goal of Sugiyama et al.:

"We don't aim to observe the way the congestion 'turns on' (Nagoya), instead we aim to fix the way to 'turn it off', i.e., determining the way to control it: which driving technique (DD / DI) promotes a higher stability to the driver trajectory, both in cognitive-affective and behavioral terms." (Blanch, 2015; p. 53).

Before coming to the data, this paragraph needs some explanation. DD stands for Driving to keep Distance (with the leading car), and DI for Driving to keep Inertia (i.e., a uniform speed). By proposing differing driving techniques we somehow oppose the idea of normative driving behavior as a unique driving mode (Brackstone \& McDonald, 1999). We assume drivers can be proactive in their decision on how to follow a leading vehicle, changing from an automatic to a controlled operative mode (Kahneman, 2011), and using DD or DI techniques simply as required.

The basic hypothesis tested on the three studies summarized below were, first that the same driver should be able to keep driving in DD mode and also in DI mode when following a lead 'disturbing' car. The second general goal was checking that drivers could assume the driving techniques in a simple manner, i.e., just following a $10 \mathrm{~s}$ instruction (one sentence). The third general goal was checking that differences in behavioral, operative terms (accelerations, decelerations, collision speed, distance to leader, fuel consumption, and so on) were statistically significant. Other goals concerning the psychophysiological (skin conductance) and cognitive responses (self-assessment concerning affective and personality factors) are out of the scope of this paper (see Blanch, 2015; Ferruz, 2015).

\section{OVERVIEW OF THE THREE STUDIES}

\subsection{Design and participants}

The three studies referred here share the same design, a repeated measures model controlling for order (AB-BA). The manipulation of the type of driving technique applied to follow the lead vehicle, either focused on Distance (DD) or focused on Inertia (DI), was the within-subject factor: the same participant driver experiences with both techniques. Order was the between-subjects factor: some participants go DD-DI, others DI-DD, always at random. The set of dependent measures concern performance indicators (accelerations, decelerations, and collisions, distance to lead vehicle, speed, overall distance and fuel consumption, registered by the simulator, table 2). The basic task of the participant consisted of advancing for 4 minutes in a simulated road, in a straight line and following a vehicle that accelerated and decelerated (until stopping) cyclically, similar to what would occur in a very congested traffic context. All participants were drivers (table 1). 


\begin{tabular}{|c|c|c|c|}
\hline & $\begin{array}{c}\text { Study 1 (Blanch, } \\
2015)\end{array}$ & $\begin{array}{c}\text { Study 2 (Blanch, } \\
2015)\end{array}$ & $\begin{array}{c}\text { Study 3 (Ferruz, } \\
2015)\end{array}$ \\
\hline $\mathrm{N}$ & 44 & 44 & 25 \\
\hline Gender $(\mathrm{n})$ & 24 women & 37 women & 12 women \\
\hline Age $($ Mean) & 23.3 years & 20.7 years & 21.3 years \\
\hline Educational level $(\%)$ & $84.1 \%$ university & $68.2 \%$ university & $100 \%$ university \\
\hline Driving experience $(M)$ & 4.07 years & 2.81 years & 2.68 years \\
\hline Km per year $(\%)$ & $59.1 \%<10000$ & $59.6 \%<10000$ & $44.0 \%<10000$ \\
\hline
\end{tabular}

Table 1 -Main demographics corresponding to participants in Study 1 and 2

\subsection{Materials}

The study was carried out in the Faculty laboratories of a Spanish University. The driving simulation software (ReactFollower, Impactware, 2014) was used to show three basic scenarios, always in a straight line: A) the participant drives alone on the road (always in a natural position on the driver's virtual side of the vehicle), B) the participant drives behind another vehicle traveling at constant speed of $3 \mathrm{~m} / \mathrm{s}(10.8 \mathrm{~km} / \mathrm{h}), \mathrm{C})$ the participant drives behind another vehicle traveling with constant cycles of acceleration-speed maintenancedeceleration-stop. These cycles are controlled by sinusoid function built at a mean speed of $3 \mathrm{~m} / \mathrm{s}$ (the data on this paper only corresponds to scenario C). Participants could only control the acceleration and deceleration of their vehicle, pressing the "up" and "down" arrows at the bottom right corner of a computer keyboard. When the "up" arrow was pressed, it accelerated, maintaining a constant speed when released. When the "down" arrow was pressed it decelerated. The acceleration-deceleration was in discrete increments, that is, to accelerate or decelerate continually the participant should repeatedly press the pertinent keys. The room was in ideal sound, light and temperature conditions for the task execution. The driving simulator worked on a computer (HP TouchSmart iq522es with a 23-inch screen, NVIDIA GeForce $9300 \mathrm{~ms}$ graphic card and 4 GB of RAM, Intel Core Duo Processor T6400 $2.00 \mathrm{GHz}$, and Windows 7 operating system). A precision Apple USB keyboard (PCB DirectIn V2012) was also used. The simulator collected the following variables: count of accelerations, decelerations and collisions with the lead vehicle, time, total distance travelled, instantaneous speed during the journey and fuel consumption.

\subsection{Procedure}

In the experimental phase proper (scenario $C$ ) the participant was invited to drive after the lead vehicle and adopt one of two basic driving techniques (DD and DI), even though the subject never received an explicit verbal description of either one. The group that carried out the task in DD-DI order, first received this instruction for DD, "In the next simulated driving scenario in which you are going to enter, you will see that there is also a vehicle ahead of you, but it will not move at a constant speed, that is, sometimes it will go faster or slower. What we ask you to do is that you travel behind that vehicle as close as possible without risking a collision." Following this, they were given the SAM scales for selfassessment of their affective state. Afterwards, they were given the next simulated 
scenario, receiving this DI instruction: "In the next simulated driving scenario, you will see that there is also a vehicle ahead of you, it will not move at a constant speed. It will sometimes go faster or slower. What we now ask you to do is that you travel smoothly behind the vehicle and maintain a constant speed, without letting the vehicle ahead move too far away." Participants in the supplementary condition (DI-DD) read the same texts in the reverse order.

\section{OVERVIEW OF MAIN RESULTS}

Operational scores were subjected to a repeated measure ANOVA having two levels of driving orientation (DD, DI). Table 2 presents the main results concerning performance in the three studies. All comparisons of the DD/DI means for each factor (accelerations, decelerations, collisions, and so on) yielded significant differences in Study 1 ( $\mathrm{p}<.001)$, Study $2(\mathrm{p}<.001)$ and Study $3(\mathrm{p}<.005)$.

\begin{tabular}{|c|c|c|c|c|c|c|}
\hline & \multicolumn{2}{|c|}{ Study 1 } & \multicolumn{2}{c|}{ Study 2 } & \multicolumn{2}{c|}{ Study 3 } \\
\hline & DD & DI & DD & DI & DD & DI \\
\hline Accelerations (n) & 147.9 & 90.1 & 158.3 & 106.6 & 230.9 & 55.0 \\
\hline Decelerations (n) & 108.5 & 55.8 & 100.7 & 62.6 & 134.2 & 31.2 \\
\hline Collisions (n) & 3.7 & 0.3 & 2.9 & 0.2 & 1.56 & 0.36 \\
\hline Fuel expenditure (l) & 19.4 & 15.0 & 18.6 & 15.1 & 19.7 & 13.9 \\
\hline Distance to leader (m) & 6.6 & 11.9 & 7.7 & 17.6 & 9.25 & 19.4 \\
\hline Distance dispersion (m) & 3.95 & 4.74 & 4.37 & 5.40 & 4.57 & 6.08 \\
\hline Speed (m/s) & 3.08 & 3.05 & 3.07 & 3.03 & 3.07 & 3.03 \\
\hline Speed dispersion (m/s) & 2.57 & 1.44 & 2.54 & 1.44 & 2.24 & .99 \\
\hline
\end{tabular}

Table 2 -Means corresponding to the main variables on the three Studies

Performance characterized DD mainly as preserving distance to leader (always shorter and within a smaller span) sacrificing, most notably, speed dispersion. DD replicates the leader disturbance, and hence it would transmit it. Performance also characterized DI mainly as preserving speed dispersion while yielding on distance and distance dispersion. DI damps the leader disturbance, and would in turn be an easier vehicle to follow. This issue was specifically checked in the third study, which included some new measures taken by the simulator: eight virtual cars where following the participants (absolutely unaware of it). The eight virtual drivers all practiced a traditional approach to follow each other (and the participant). The simulator registered the distances between the leader and the $8^{\text {th }}$ vehicle, and also between the participant and the $8^{\text {th }}$ vehicle. The results indicate that the averaged distance between the lead vehicle and the $8^{\text {th }}$ vehicle was similar under each condition (DD: $M=117.3 \mathrm{~m}, S D=1.93$; DI: $M=118.95 ; S D=8.75$ ). However as shown in table 2 the distance between participant and leader is larger under DI. But most importantly, also the differences between the participants' vehicle to the $8^{\text {th }}$ vehicle were measured under each condition (DD: $M=108.03 \mathrm{~m}, S D=1.93$; DI: $M=99.55 ; S D=3.69$ ), yielding significant 
differences, $F_{(1,23)}=30,32, p<, 001$. The DI technique furnishes platoon stability, resulting in an optimization of space on the road. Overall, a good global indicator of performance in the three studies is the virtual fuel expenditure, always around a $20 \%$ lower under DI.

\section{CONCLUDING REMARKS}

Modern societies face a controversial issue: we eliminate part of the pollution generated by road traffic by breathing it, this causing already more deaths than road crashes (Caiazzo et al., 2013). Pollution and congestion join because the transient driving modes (acceleration and deceleration) are the most contaminant (Tong et al., 2000). This paper aims to connect the most recent trends concerning car-following models (Melchor \& Sánchez, 2014; Sugiyama et al., 2008) with our first attempts to contrast how the potential contribution of drivers to the betterment of traffic flows could be. All in all, it seems that drivers have been instructed to follow a mobile, but they should learn to follow its average speed instead. For doing so, drivers need to learn that safety distance need to be combined with a third variable: the efficiency distance. Abstract as it seems, drivers under DI did it quite clearly.

We are not obviating the fact that conceptual models have still to grow on physical and mathematical complexity in order to help optimize the current road network (several lanes, differing speeds, overtaking, merging). However, whatever the progression of such analysis, and provided that the right training and education is given to them, our view is that the role of individual drivers in modern road traffic should be seriously reconsidered. This view concerns human drivers, of course, but also the automated ones, frequently announced in our days. Longitudinal mechanical waves are instruments of nature serving different types of movement, and robots are not free of such allegiance. Perhaps, under this common stance integrating automated and human driving is not so difficult after all.

\section{AKNOWLEDGEMENTS}

We thank Alberto Arbaiza (DGT), and Professors Anxo Sánchez (Universidad Carlos III de Madrid) and José Luís Toca-Herrera (BOKU, Vienna) for their kind suggestions for improvement. This paper has been written with the support of the Fundación Universitaria Antonio Gargallo y Obra Social Ibercaja, Spain, under grant 2014/B001: Influencia de la respuesta cognitivo-emocional en el comportamiento vial. Simulación educativa, autoregulación e implicaciones en la conducción armónica.

\section{REFERENCES}

BLANCH, M.T. (2015) El seguimiento de un vehículo en el desplazamiento en línea: caracterización psicofisiológica y conductual de dos formas básicas de conducción. Tesis Doctoral. Universitat de València.

BOER, E. R. (1999). Car following from the driver's perspective. Transportation Research Part T, 2, 201-206.

BRACKSTONE, M., MCDONALD, M. (1999) Car-following: a historical review. 
Transportation Research Part F, 2, 181-196.

CAIAZZO, F., ADHOK, A., WAITZ, I., YIM, S., BARRET, S. (2013). Air pollution and early deaths in the United States. Part I: Quantifying the impact of major sectors in 2005. Atmospheric Environment, 79, 198-208.

CROMER, A. H. (1981). Física para las ciencias de la vida. Barcelona: Editorial Reverte. FERRUZ, A.M. (2015). Análisis de la intervención del factor humano en el movimiento vehicular en línea a partir de dos modelos de conducción. Trabajo Fin de Grado. Universidad de Zaragoza.

FITZGERALD, T.D. (2003). Role of trail pheromone in foraging and processionary behaviour of pine processionary caterpillars Thaumetopoea pityocampa. Journal of Chemical Ecology, Vol. 29, No. 3, March, 513-532.

GAZIS, D.C., HERMAN, R. (1992) The moving and "phantom" bottlenecks. Transportation science, Vol. 26, No. 3, 223-229.

GIL, H. (2015). Aprender de los animales para mejorar el tráfico. Tráfico y Seguridad Vial, $\mathrm{N}^{\mathrm{o}}$ 230. Madrid: DGT, 38-41.

KAHNEMAN, D. (2011) Thinking, fast and slow. New York: Farrar, Straus and Giroux.

LUCAS, A. (2009) Psicología social del tráfico: del conductor individual a la interacción entre conductores. Tesis Doctoral. Universitat de València.

MELCHOR, O., SÁNCHEZ, A. (2014). Conducir con tres variables. Documento interno IMPACTWARE/Universidad Carlos III de Madrid.

PARIOTA, L., BIFULCO, G.N. (2015). Experimental evidence supporting simple Action Point paradigms for car-following. Transportation Research Part F, 35, 1-15.

RANNEY, TH. A. (1994) Models of driving behavior: a review of their evolution. Accident Analysis \& Prevention, 26, 6, 733-750.

SAIFUZZAMAN, M., ZHENG, Z. (2014). Incorporating human-factors in car-following models: A review of recent developments and research needs. Transportation Research Part F, 48, 379-403.

SUGIYAMA, Y, FUKUI, M, KIKUCHI, M, HASEBE, K, NAKAYAMA, A, NISHINARI, K, TADAKI, S., AND YUKAWA, S. (2008). Traffic jams without bottlenecks experimental evidence for the physical mechanism of the formation of a jam. New Journal of Physics, 10(3):3001, March 2008.

TONG, H.Y., HUNG, W.T., CHEUNG, C.S. (2000) On-Road Motor Vehicle Emissions and Fuel Consumption in Urban Driving Conditions. Journal of the Air \& Waste Management Association, 50:4, 543-554.

TRANSPORTATION RESEARCH BOARD (2010): Highway Capacity Manual. $5^{\text {th }}$ Edition. National Research Council. Washington D.C., EEUU.

WEINGROFF, R.F. (1996) Federal-Aid Highway Act of 1956: Creating The Interstate System. Public Roads. Vol. 6, No 1. Retrieved January 25, 2015: http://www.fhwa.dot.gov WIENER, N. (1989). The human use of human beings. London: Free Association Books. 